\title{
Técnicas y lenguajes documentales por el brasileño Eduardo Coutinho
} Technical and documentary language by
Brazilian Eduardo Coutinho

D Renó [ $[\underline{\mathrm{CV}}]$ [ORCID] [GS] Profesor del Departamento de Comunicación Social - Universidad Estadual Paulista, Unesp, Brasil - denis.reno@faac.unesp.br

C Campalans Moncada [CV] [GS] Profesora del Programa de Periodismo y Opinión Pública Universidad del Rosario, UR, Colombia - carocampalans@ gmail.com

L Renó [CV] [GS] Profesora del Programa de Radio y Televisión - Universidad Estadual Paulista, Unesp, Brasil - luciana.lorenzi@gmail.com

\begin{abstract}
s
[ES] 1. Introducción. Eduardo Coutinho representa el desarrollo y la innovación del documental brasileño. Todavía, su trayectoria es marcada por una técnica novedosa de entrevistas con los participantes, además de la mezcla del documental con otras técnicas comunicacionales, especialmente la ficción y el periodismo. Este artículo ofrece una recuperación de la trayectoria de Coutinho y de sus principales obras. 2. Método. Se aplica una investigación bibliográfica y una análisis de discurso fílmico para comprender la trayectoria y los lenguajes adoptados por Coutinho durante su carrera como documentalista. 3. Quien fue. Antes de actuar como documentalista, Coutinho ha estudiado Derecho pero siempre actuó con teatro y artes visuales. Esa discusión presenta Coutinho antes de los documentales. 4. Encuadres de Eduardo Coutinho. Las principales obras del documentalista son presentadas, así como sus características importantes que transforman la filmografía del director en una de las más importantes de Brasil. 5. Conclusiones. Se concluye que Eduardo Coutinho ha dejado un hueco en el documental brasileño, desde su muerte en 2014. Sin embargo, sus contribuciones son transformaron el género, como presentado en los resultados del artículo.
\end{abstract}

[EN] 1. Introduction. Eduardo Coutinho represents the development and innovation of the Brazilian documentary. His career is still marked by a novel technique of interviews with participants also mix 
documentary with other communication techniques, especially fiction and journalism. This article provides a recovery path Coutinho and his major works. 2. Method. A literature review and analysis of filmic discourse is applied to understand the history and languages adopted by Coutinho during his career as a documentary. 3. Who was. Before acting as a documentary, Coutinho has studied law but always acted in theater and visual arts. This discussion presents Coutinho before documentaries. 4. Frames by Eduardo Coutinho. The main works of the documentary are presented, as well as its important features that transform the filmography of director in one of the most important in Brazil. 5. Conclusions. We conclude that Eduardo Coutinho has left a gap in the Brazilian documentary, since his death in 2014. However, their contributions are transformed the genre, as the results presented in the article.

\section{Keywords}

[ES] Comunicación, Narrativas audiovisuales, Documental, Lenguaje.

[EN] Communication, Audiovisual narratives, Documentary, Language.

\section{Contents}

[ES] 1. Introducción. 2. Método. 3. Quien fue. 4. Encuadres de Eduardo Coutinho. 5. Referencias bibliográficas. 6. Filmografía.

[EN] 1. Introduction. 2. Method. 3. Who was. 4. Frames by Eduardo Coutinho. 5.

Bibliographicreferences. 6. Filmography

\section{Introducción}

El día 2 de febrero de 2014, el cine documental dejó de contar con uno de sus autores más relevantes, especialmente en lo relativo a las innovaciones en el campo narrativo y de la investigación. En esa fecha, Eduardo Coutinho murió asesinado por uno de sus hijos, que, en un momento de ira, apuñaló a su padre con un cuchillo. Era el final de una historia marcada por cabras, Edificio Master, Peões, entre otros personajes cinematográficos que pasaron por sus encuadres a lo largo de casi cincuenta años, aunque empezó en el cine incluso un poco antes, con la gestión de la producción del largometraje Cinco vezes favela (1962), producido por un grupo de cineastas del Centro Popular de Cultura-CPC.

Pero Eduardo Coutinho es inmortal para el cine documental brasileño, especialmente porque revolucionó la producción audiovisual del país y porque formó parte de un momento histórico del séptimo arte -el cine nuevo-, experimentando narrativas y estéticas para el documental, mientras el mundo seguía corrientes tradicionales y/o trabajaba con obras de ficción.

Efectivamente, Coutinho experimentó con un nuevo lenguaje, produciendo una ficción definida como cine híbrido (Renó, 2013), ya con los primeros registros de la obra $O$ Cabra, que alcanzó su segunda semana de rodaje, hasta que el Golpe Militar de 1964 prohibiera su producción. Se trataba de una ficción basada en la historia real del líder campesino João Pedro Teixeira, asesinado a causa de su liderazgo político y social. En el film, personajes reales representarían sus propios papeles; como su esposa, Elisabeth Teixeira, que encarnaría su propio personaje.

El cine es construido a partir de revoluciones de lenguaje, aunque la estructura lineal del arte no ha cambiado desde su creación. Según Reia-Bptista, Burn, Reid y Cannon (2014), "un cinéfilo que entra en coma en 1926 y se despierta en 1986 reconocería el medio aunque desconociera los nuevos estilos de peinado". 
Aunque la filmografía de Eduardo Coutinho sea conocida especialmente por la semejanza con la posición de Jean Rouch y Edgar Morin en Crónica de un verano, en la cual los documentalistas son, al mismo tiempo, actores (cinema vérité), el elemento diferencial está en la manera cómo obtenía las respuestas y la participación de sus personajes, empleando una técnica de entrevista conocida como "rescate de la memoria de imagen" (Gervaiseau, 2012), popular también en las obras de otro documentalista, el francés Claude Lanzmann. También es importante apuntar que el público ha cambiado (Renó, 2008), lo que exige la creación de nuevos modelos narrativos.

\section{Método}

El artículo presenta una biografía de Eduardo Coutinho y una reflexión crítica sobre algunas de sus más importantes obras (aunque todas sus obras fueron igualmente importantes, teniendo en cuenta su contribución cuadro a cuadro al documental). Para ello, se adopta como metodología la investigación bibliográfica y el análisis del discurso fílmico, obteniendo al final un registro sobre la trayectoria de aquél que fue uno de los más importantes artistas del cine de no ficción que Brasil haya conocido.

El modelo de análisis del discurso fílmico es un método de estudio sobre cine que, según Vanoye y Goliot-lété (2008), se traduce en redactar conclusiones a partir de la observación audiovisual del contenido, desde sus técnicas de producción como del lenguaje adoptado. Esto es lo que se presenta en el estudio, a partir de una selección de las más importantes obras documentales de Eduardo Coutinho.

\section{Quién fue}

Para conocer a Eduardo Coutinho no basta con observar sus obras, aunque ellas cuenten por sí mismas con la capacidad de expresar las cualidades del cineasta. Aun así, es importante conocer la formación de Coutinho para, de ese modo, descubrir de dónde provienen sus técnicas y su estética. Esto se justifica particularmente porque un profesional se hace no sólo a partir de lo que ha estudiado, sino también de su bagaje personal.

Los productos desarrollados por Eduardo Coutinho no podrían estar ajenos a esa realidad. Nacido el 11 de mayo de 1933 en Río de Janeiro, Coutinho estudió Derecho en la Universidad de São Paulo una de las más importantes del país-, pero no concluyó su formación. Al igual que muchos otros estudiantes de la época, decidió trabajar en el ámbito de la cultura y la comunicación. En 1954 inició su relación con el arte y el cine, trabajando como revisor de la revista Visãoy como director de teatro en el espectáculo infantil Pluft, o fantasminha. Además, en un concurso de televisión, ganó dinero respondiendo preguntas sobre Charles Chaplin. Con el premio viajó a Francia a estudiar dirección y montaje cinematográfico en el IDHEC. Allí realizó sus primeros documentales.

De regreso en Brasil, ingresó en el grupo de realizadores del popular Cine Nuevo, integrando el Centro Popular de Cultura de la Unión Nacional de los Estudiantes (conocido por la sigla CPC da UNE). Con el grupo participó en montajes de espectáculos de teatro, dirigidos a la sociedad (con discursos populares) y actuó como gerente de producción del largometraje Cinco vezes favela (1962), que contó con cineastas importantes del Cine Nuevo, como Cacá Diegues o León Hirzsman, entre otros. Con Hirzsman y Marcos Faria, Coutinho creó la productora Saga Filmes y en ella fue director 
de algunas obras de ficción, como $O$ Pacto (que integra el largometraje $A B C$ do Amor, 1966), $O$ homem que comprou o mundo (1968) y Garota de Ipanema (1967), entre otros.

En 1975, Eduardo Coutinho fue invitado a trabajar en el equipo del programa Globo Repórter, de Rede Globo, donde permaneció hasta 1984. Lo que marcó su paso por el programa fue la libertad editorial y la posibilidad de producir todo en $16 \mathrm{~mm}$. Ese fue el momento en que Globo Repórter ganó notoriedad por sus producciones semidocumentales. Las improntas de esa formación podemos detectarlas en el estilo de Coutinho, presente en todas sus obras documentales.

Como veremos más adelante, Eduardo Coutinho tenía un estilo particular de actuación en sus documentales, además de una técnica de entrevista muy peculiar. Estos rasgos son propios de quien estudió Derecho, además de haber desarrollado y descubierto el cine en la Francia de 1960; es decir, en el momento en que el Cinema Vérité (Nichols, 1997) ganaba fuerza a partir de obras como Crónica de un verano, de Jean Rouch y Edgar Morin.

Así como Rouch/Morin, Eduardo Coutinho participaba en todas sus obras como personaje que preguntaba, que dialogaba con los entrevistados. Es una técnica que inserta al documentalista en la historia, compartiendo con ello la credibilidad de lo que es revelado en la narrativa. Ello venía ocurriendo desde el principio de su filmografía. Aunque Cabra marcado para morrer fue presentada en 1985, fue la primera obra producida por Coutinho, en 1964, cuando la Dictadura Militar declaró prohibida dicha producción. En esa obra, Eduardo Coutinho no participaba directamente, como era su estilo, mas construía una narrativa híbrida a partir de la interpretación de los personajes por sus protagonistas en la vida real. Pero al finalizar la obra, 21 años después, el cineasta produjo una estética totalmente cinema vérité, con un personaje fundamental en toda la narrativa: Eduardo Coutinho -el mismo que fue a aprender cine a Francia, cuando Jean Rouch y Edgar Morin enseñaban al mundo lo que era el cinema vérité.

Otra característica de Coutinho, que provenía de su formación, era la manera cómo descubría las informaciones. Para ello, el cineasta adoptaba como técnica el rescate de la memoria de la imagen, empleada por algunos pocos cineastas, como el francés Claude Lanzmann, autor de importantes obras documentales. Su principal obra es "Shoah" (1985), que presenta en 9,5 horas escenas sin textos o voz over. Además, es una obra debatida no solamente por el tiempo de duración de la película, sino también por la técnica adoptada y la adopción de cámara oculta, considerada por algunas corrientes como no permitida en documentales. Con esta técnica, Coutinho promovía un diálogo, que venía a ser al mismo tiempo un interrogatorio, con pruebas físico/visuales/sensitivas. Por ejemplo, en casi todas sus obras, Coutinho presentaba al entrevistado algo que provocaba la evocación de algún hecho ocurrido en el tiempo que interesaba al documental. A partir de la reacción de memoria sobre el objeto (podía ser una fotografía, una prenda de ropa, una herramienta, una pieza de comida o incluso una situación), Coutinho introducía las preguntas. Es imposible contener la emoción al revisar algo, o incluso sostener la mentira cuando se está frente a una verdad (pues la prueba es una verdad). Ésa, seguramente, era una técnica que surgió a partir de las técnicas conocidas en el programa de Derecho, donde Eduardo Coutinho fue estudiante por un tiempo. Y es su principal característica, aparte de otras que veremos más adelante.

\section{Encuadres de Eduardo Coutinho}

Aunque algunos documentales destaquen como los más conocidos, es muy difícil descubrir cuáles son las principales obras de Eduardo Coutinho. Ello se debe a su diferencia con respecto a los demás artistas de su tiempo, especialmente de Brasil, y también por la capacidad de crear una estética y una 
técnica de producción documental que incluso llega a provocar que algunos académicos lo definan erróneamente como teórico. En realidad, Coutinho no fue un teórico y ni siquiera era ése su interés. Aunque haya experimentado con muchas técnicas que podrían transformarse en teorías (y que surgían de su cabeza con esa característica), Coutinho no las defendió, dejándolas dispersas en el territorio académico. Eso es común entre cineastas que probaron diversas técnicas de producción, aunque no las transformaron en teorías, como DzigaVertov, que desarrolla algunos manifiestos, solamente.

Pero entre sus obras, seguramente, Cabra marcado para morrer es la más importante. Según Henri Gervaiseau (2000), la obra es para el cine documental brasileño lo mismo que El hombre de la cámara (1992), de DzigaVertov, para el documental mundial. A partir de esta obra, no solamente se descubrieron técnicas documentales, sino que también se consiguió una difusión más significativa del género en el país.

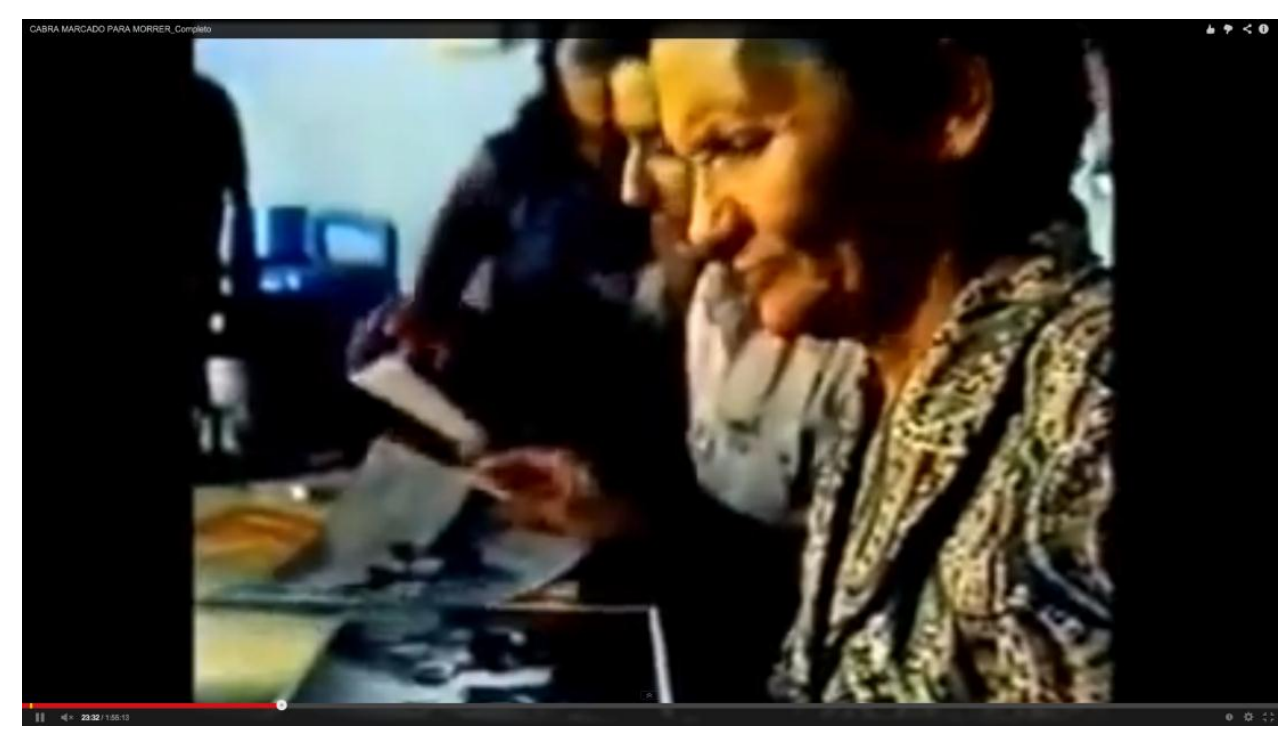

Imagen 01: "Cabra marcado para morrer", con el rescate de la memoria de la imagen como técnica.

Inicialmente fue ideada para contar la historia del asesinato del líder de las Ligas Campesinas, João Pedro Teixeira. En la película, diversos personajes asumirían la interpretación de su propio papel, como Elizabeth Teixeira, viuda de João Pedro, que se recreaba a sí misma en la película. Lamentablemente, cuando llevaba dos semanas de rodaje, los militares ejecutaron el Golpe Militar de 1964 y prohibieron la producción.

En 1985 y con pocas imágenes producidas (pero suficientes para emprender un nuevo proyecto), aquello que debía ser una película de ficción de realidad pasó a ser un documental, en el que Elizabeth Teixeira intentaba encontrar a sus hijos por diversos puntos del país. A cada momento, Eduardo Coutinho (uno de los personajes, que ayudaba a Elizabeth) exhibía escenas de la producción original y registraba las reacciones de los participantes en el momento actual. Esto es fundamental para la obra -la reacción de los participantes-, pues allí estaba la noticia, especialmente cuando el tema era Brasil antes y después de la Dictadura Militar. El documental recibió 12 premios internacionales, distribuidos en países como Brasil, Cuba, Francia, Alemania, Portugal, etc. 


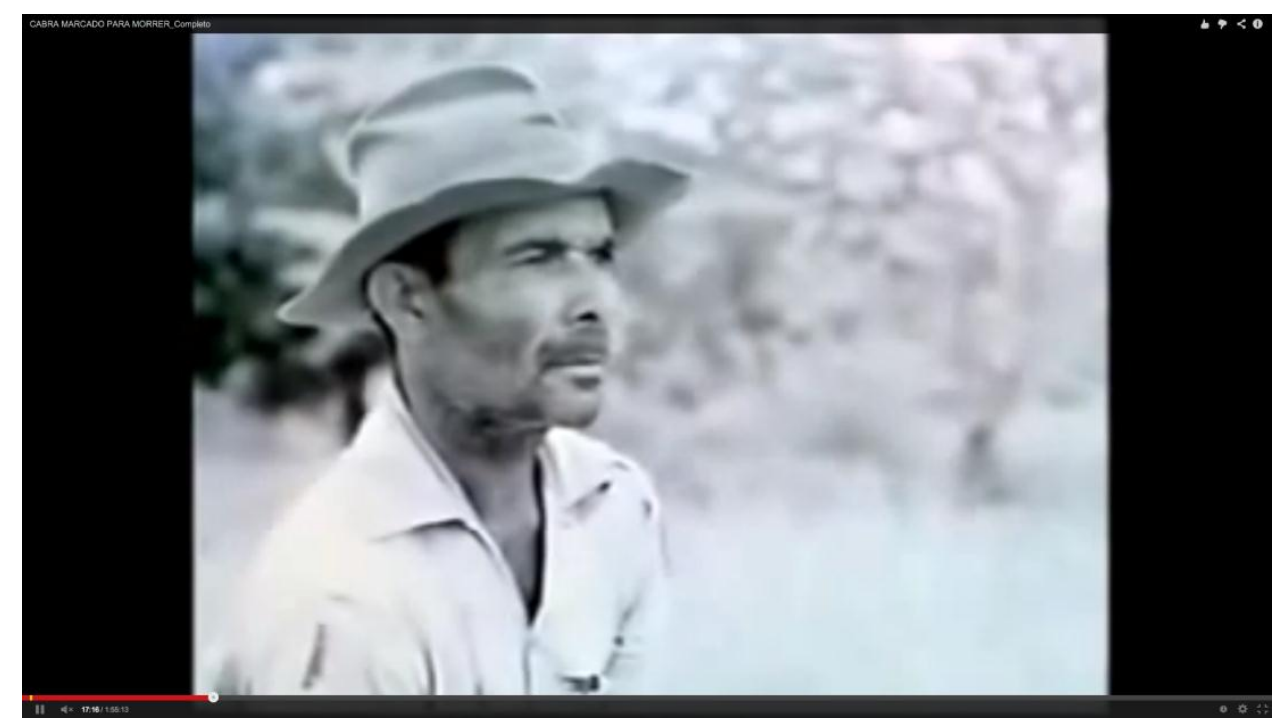

Imagen 02: Versión original (ficción de realidad) de "Cabra marcado para morrer”.

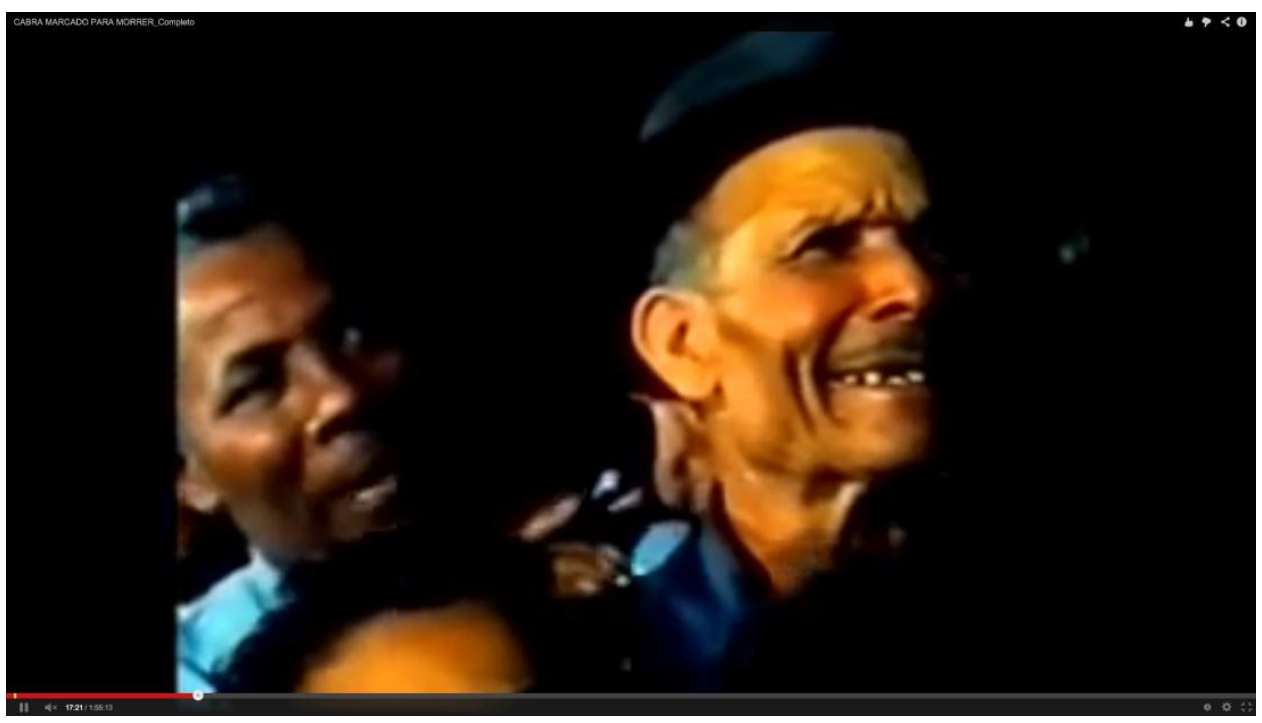

Imagen 03: El mismo personaje en la versión documental de "Cabra marcado para morrer".

A partir de Cabra marcado para morrer, Coutinho ganó notoriedad en el medio audiovisual, dejando el programa Globo Repórter y pasando a dedicarse a la producción de documentales en videos para el CECIP, Centro de Creación de la Imagen Popular, con contenidos relacionados con la ciudadanía y la educación. Es entonces cuando surgía una obra fundamental en su trayectoria: Santa Marta Duas semana no morro (1987). En la obra, Coutinho presentaba temas relacionados con el prejuicio y la violencia urbana y se proponía dejar en evidencia las condiciones precarias para la producción del documental. Era la primera vez que se exponía la relación entre favela y ciudad después de Cinco vezes favela, de 1962. 


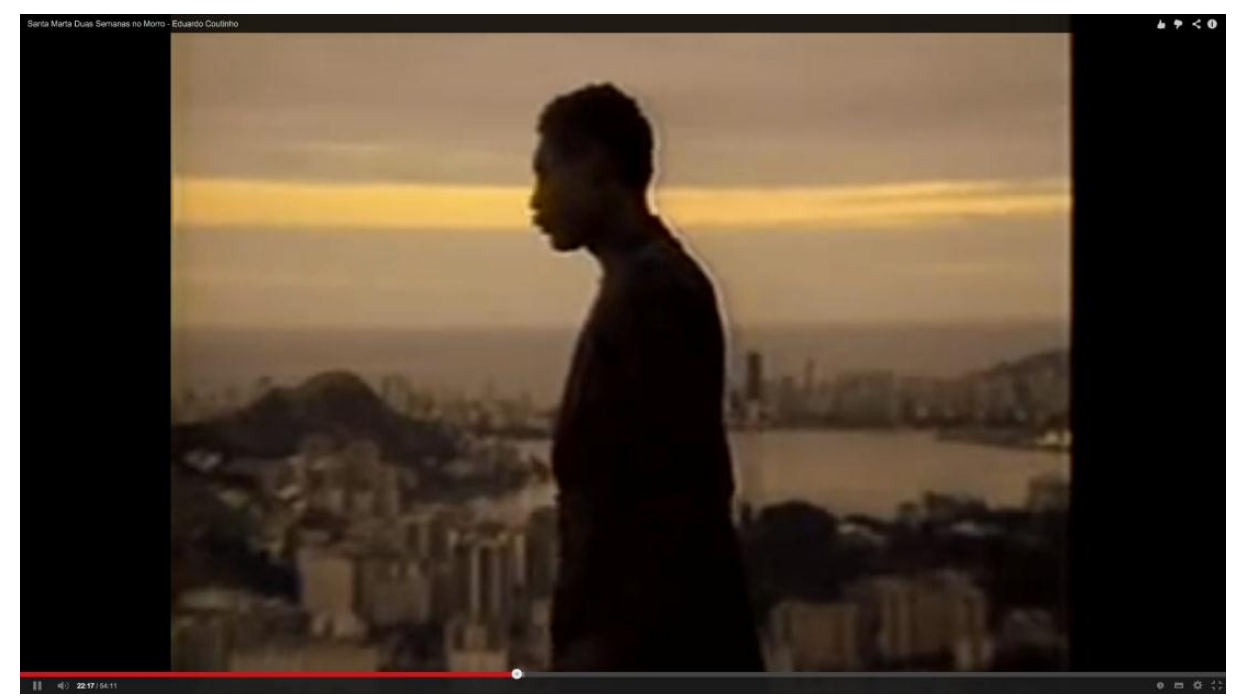

Imagen 04: "Santa Marta -duas semanas no morro".

Pero en otro momento, Eduardo Coutinho volvía a las favelas cariocas (gentilicio asignado a las personas que nacen en Rio de Janeiro, Brasil), aunque con un argumento central diferente. En Babilonia 2000 (2000), el documentalista se propuso retratar cómo los personajes de las favelas de Río de Janeiro esperaban el nuevo siglo y, obviamente, los valores que los diferenciaban respecto a los habitantes de las regiones pudientes de la ciudad.

Entre dichos valores se encontraba la preocupación por el futuro, la violencia y el sexo. Coutinho pasó a convivir con algunos moradores de favelas durante los preparativos finales de la fiesta de Año Nuevo. Se trata de registros especiales, pues los noticieros siempre cubren los preparativos de los ciudadanos de mejores condiciones económicas y no los de los habitantes de la favela carioca.

En esa obra, Eduardo Coutinho se dio a conocer como un ciudadano preocupado efectivamente por registrar a los ciudadanos de verdad y no el cuento de hadas, el sueño americano que conocemos en algunas obras audiovisuales. Según Jean-Claude Bernardet (2003), Eduardo Coutinho consiguió mostrar al pueblo como es, sin maquillaje, sombras ni falsas sonrisas.

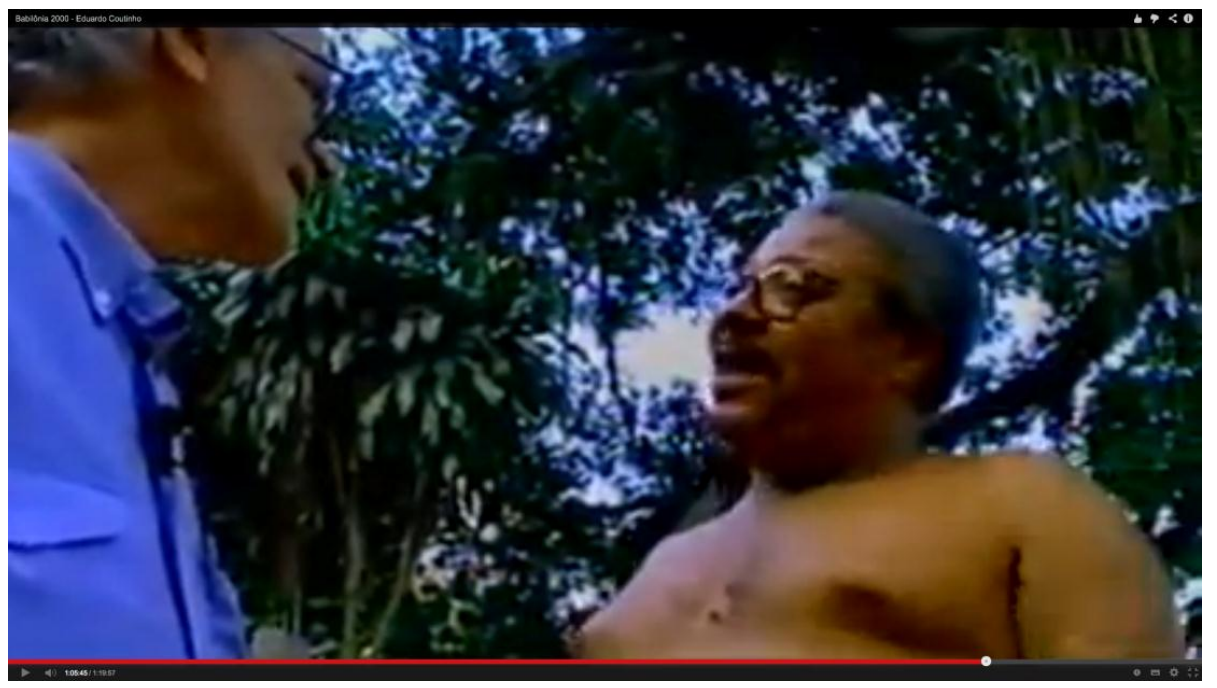

Imagen 05: Los personajes Eduardo Coutinho y Dody, en "Babilônia 2000”. 
Otra obra innovadora de Coutinho fue Edificio Master (2002), para la cual el director decidió vivir durante tres semanas dentro del edificio, con todos los integrantes de la producción. El edificio estaba situado en una región noble de Río de Janeiro, pero contaba con aproximadamente 500 habitantes pertenecientes, en gran parte, a los estratos más bajos.

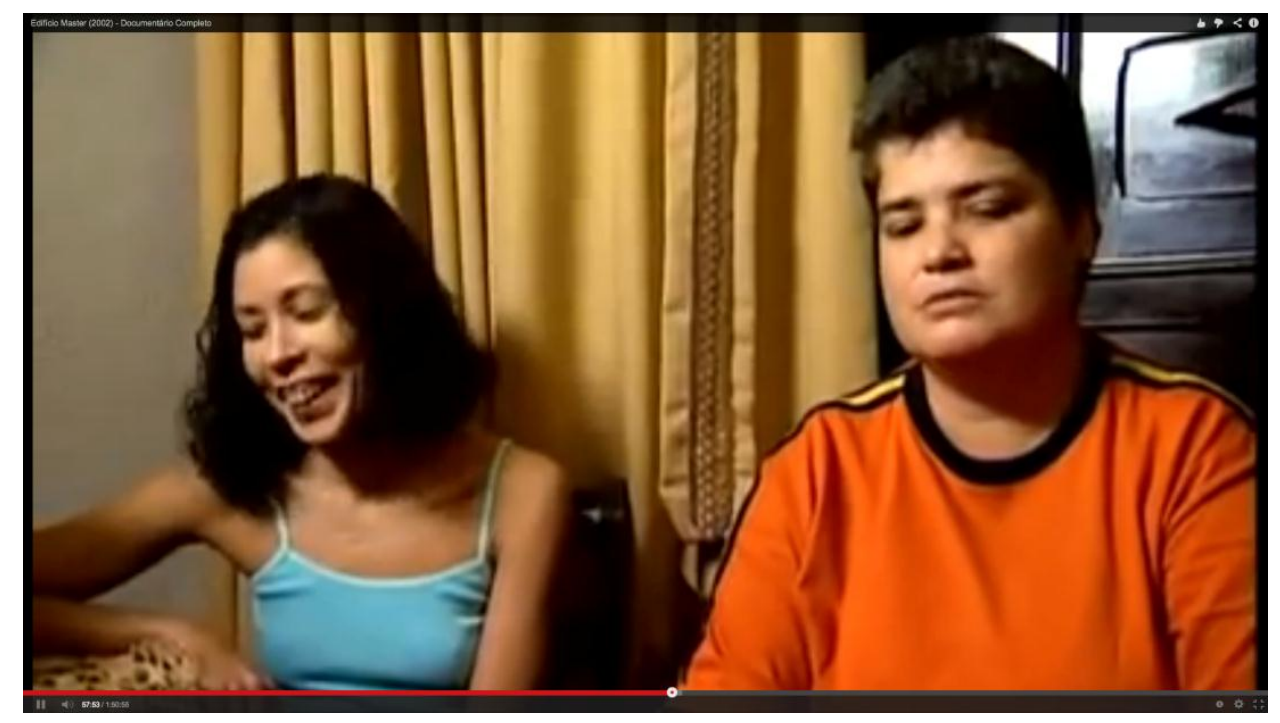

Imagen 06: Personajes durante entrevista en "Edificio Master".

En el documental, Eduardo Coutinho empleaba una mezcla de técnicas del periodismo gonzo, creado por el periodista estadounidense Hunter Thompson, quien desarrollaba sus trabajos periodísticos a partir de una inmersión en el tema (algunas veces de manera exagerada).

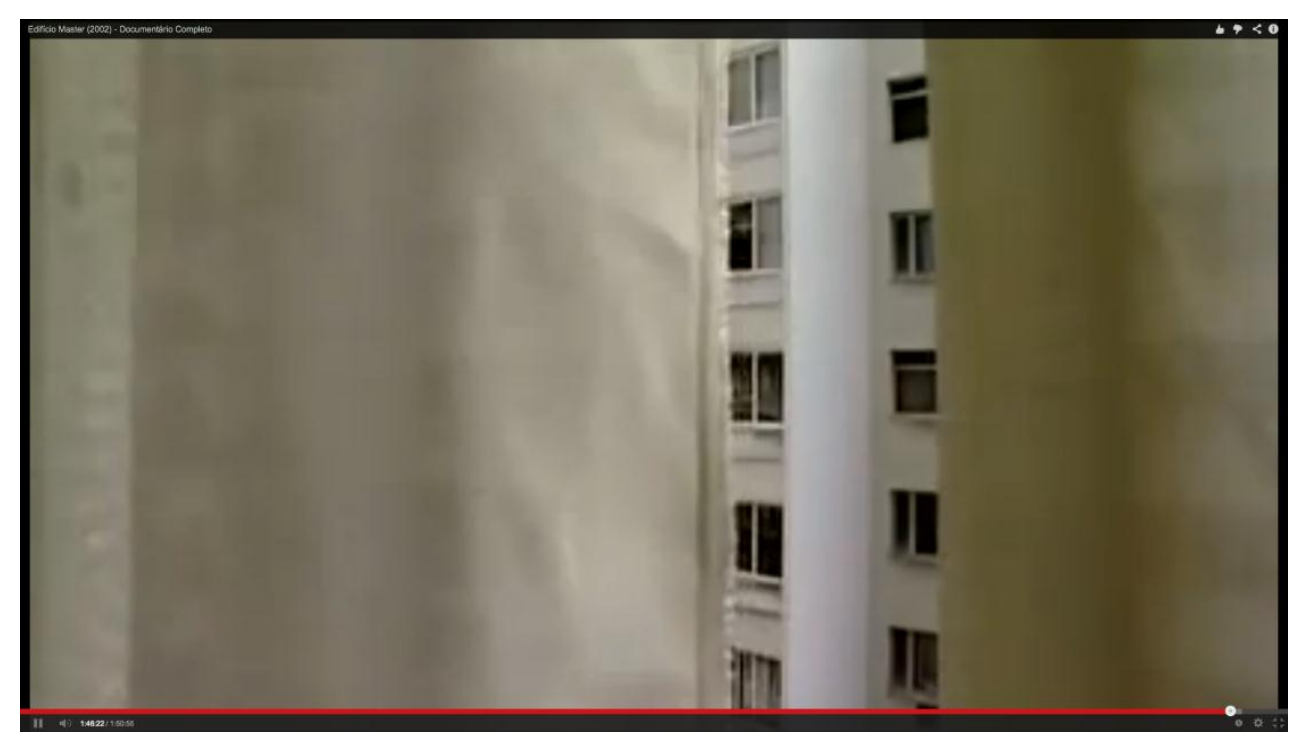

Imagen 07: Residencia de Coutinho durante las grabaciones de "Edificio Master".

La obra desplegaba un amplio repertorio de miradas, desde la perspectiva de sus propios habitantes, manifestando, incluso, sus variadas personalidades. Cada uno de ellos ofrecía sus impresiones sobre los vecinos y también sobre la vida al interior de un conjunto habitacional en el que convivían más 
de 500 familias, las cuales exhibían una notable diversidad social, cultural, sexual y religiosa, semejante a la de una ciudad. Con el apoyo casi exclusivo de entrevistas, Coutinho montó una obra básicamente sin imágenes de apoyo; éstas se presentaban sólo en la apertura y el final.

Ahora bien, uno de los trabajos de Coutinho más expresivos en materia de experimentación e innovación fue el documental Jogo de cena (2007), que hacía una mezcla directa y casi imperceptible entre ficción y realidad. Con ese fin, el director publicó una nota en un periódico, invitando mujeres a contar sus historias personales. En un estudio, 83 candidatas se presentaron y revelaron sus vidas ante una cámara. A partir de esa primera aproximación, 23 historias se escogieron para ser representadas nuevamente frente a una cámara, pero esta vez por actrices -con sus propias interpretaciones y emociones- y en el teatro Glauce Rocha, en Río de Janeiro. Al final, ¿se trataba de un documentalista haciendo ficción?

Eduardo Coutinho definía su obra como un "documental impuro", por ofrecer contenidos reales, pero por medio de nuevas voces, de nuevas mujeres, con nuevas emociones (reales o no) a partir de lo real. Y lo hacía de manera sensible y conmovedora, construyendo una relación tenue entre la ficción y la realidad, dando materialidad a aquella discusión existente entre Roger Odin y Christian Metz sobre ficción y realidad. Los dos franceses defendían interpretaciones contrapuestas en relación con la existencia de la realidad fílmica. Para Christian Metz (Renó, 2012), no existía documental, pues toda interpretación estaría construida a partir de la autoedición por parte del entrevistado. Nadie dice lo que piensa, pues teme ser malinterpretado. Por su parte, Roger Odin (1984) consideraba que no existía obra de ficción, pues todo actor, al interpretar, traería consigo un poco de su personalidad y su impronta personal. Es decir, todo personaje de ficción tendría al menos un poco de realidad. Todo es documental.

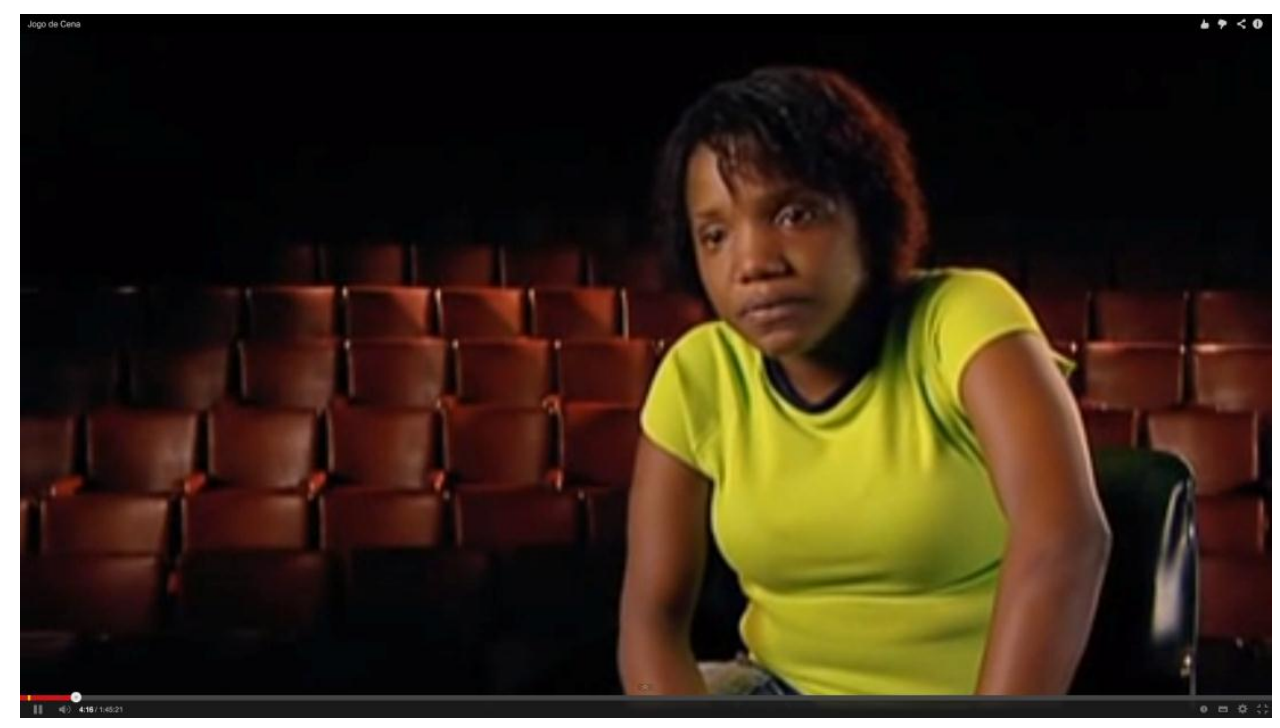

Imagen 08: Personaje hablando de sí en "Jogo de cena".

Coutinho representó esa discusión sobre el documental de una manera artística, como siempre lo hizo, pero esta vez con la ayuda de actrices, algunas profesionales y otras desconocidas. Estableció un juego entre la ficción y la realidad. En una entrevista, justificó su juego, diciendo que "una cosa bien contada es verdadera, sin preguntarnos si ella es verdadera o no. Bien contado, todo es 
verdadero". Con base en dicha experimentación, una revisión sobre los conceptos de documental y de la distancia entre el documental y la ficción pasa a ser necesaria. Bill Nichols, Fernão Ramos, Roger Odin, entre otros teóricos del cine documental, merecen ser reconsiderados, pues la esencia del experimento en este juego de escena de Coutinho -aunque él mismo no defienda la tesis- puede transformarse en nuevos e interesantes conceptos teóricos sobre el documental.

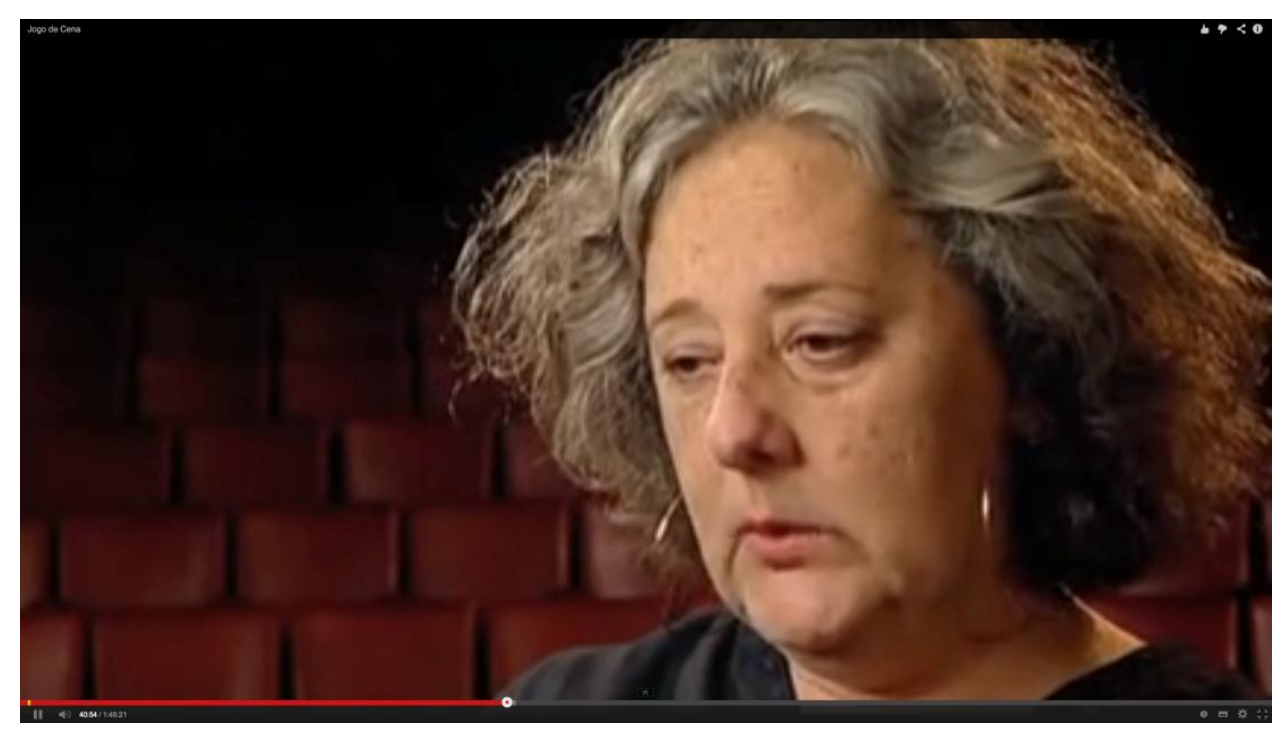

Imagen 09: Personaje desconocido de "Jogo de cena", hablando de su vida.

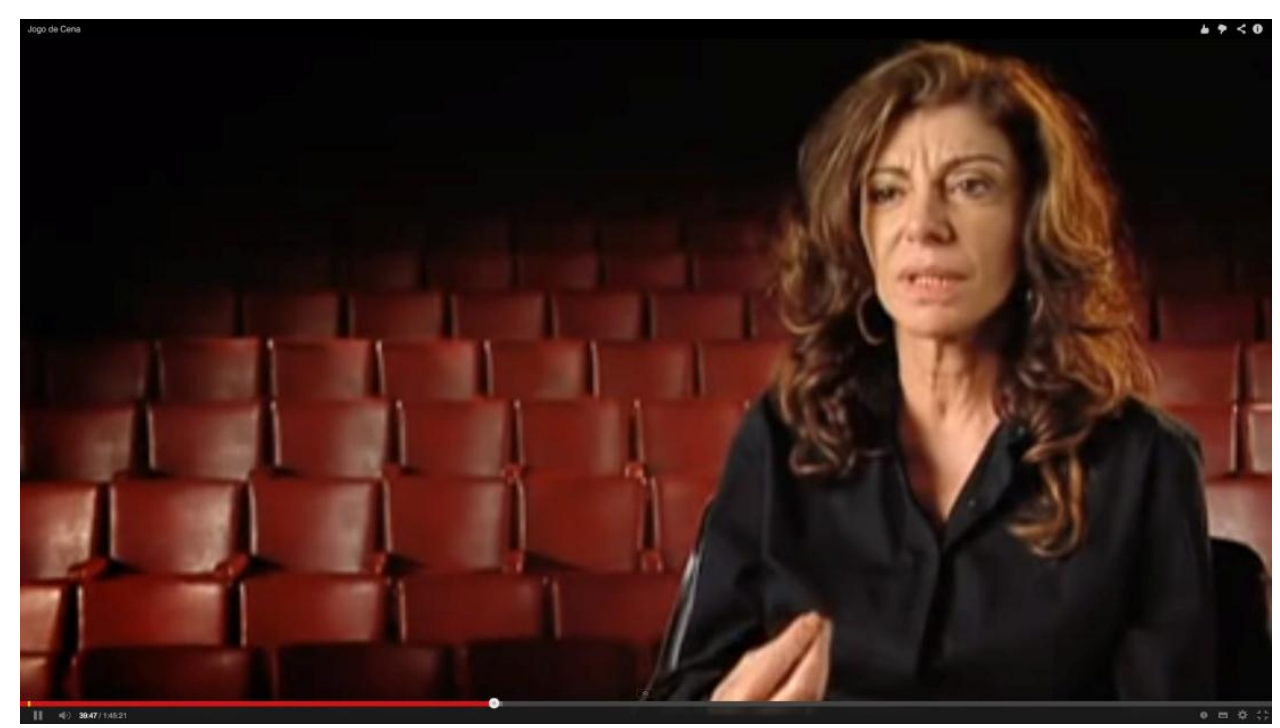

Imagen 10: Escena de "Jogo de cena", con la actriz MaríliaPêra haciendo una mezcla de historias de otros personajes.

En realidad, toda la filmografía de Eduardo Coutinho merece una atención especial, ya sea en lo que concierne a la experimentación, la preocupación social y ciudadana, el campo artístico o incluso como reflexión acerca del propio género. En todos esos terrenos, Coutinho siempre ofreció sus contribuciones y lo hizo con imágenes en movimiento, lo cual es precisamente el rasgo diferencial 
del cine. Eso es, de alguna manera, lo que hizo Kuleshov, al crear la mujer ideal (fenómeno conocido como el efecto Kuleshov) para justificar la importancia -y el poder- del montaje audiovisual para construir verdades o impresiones. Resulta injusto -como, por lo demás, nos vemos obligados a hacer en este texto- escoger sólo algunos ejemplos entre toda su obra. Pero, al mismo tiempo, es un ejercicio académico necesario y también una invitación a conocer mejor "los encuadres" de Eduardo Coutinho, a partir de la filmografía que se puede encontrar parcialmente en internet.

\section{Conclusiones}

Como se dijo al principio, el mundo del cine documental perdió uno de sus más importantes autores, reconocido incluso por la Academia de Hollywood, que lo invitó a participar como miembro de su jurado a partir de 2014. No pudo asumir el nombramiento, debido a la fatalidad de su muerte. Aunque no se pueda decir que la academia estadounidense realice siempre las mejores elecciones, la nominación de Eduardo refleja en alguna medida la relevancia de este cineasta para el cine documental.

Seguramente, Coutinho es mucho más que sinónimo de buenas obras documentales. El director ofreció a la sociedad una manera de contar las historias y de observarlas. Al construir Cabra marcado para morrer, introdujo la técnica de rescate de la memoria de la imagen, haciendo que los participantes dejasen aflorar frente a la cámara sus emociones, a partir de sus recuerdos. Y, en forma paralela, ofreció un debate sobre Brasil con y sin dictadura militar (de cierta manera, introduciendo un debate social del mismo nivel que el que propuso Crónica de un verano, de Jean Rouch y Edgar Morin).

En Santa Marta-duas semanas no morro, experimentó por dos semanas lo que podría ser una investigación gonzo y volvió a adoptar esa técnica de apropiación e inmersión en Edificio Master, esta vez con una sensibilidad de aún mayor profundidad. Consiguió que sus sensaciones en relación con el conjunto habitacional fueran casi tan reales como las de los moradores que allí construían sus historias cotidianas.

Las secuencias de Babilônia 2000 son de un Eduardo Coutinho periodista, aunque no haya sido ésa su formación académica. En ellas, el cineasta presentó al mundo una sociedad desconocida, así como sus deseos, sueños y esperanzas. En realidad, un mundo que los periódicos deberían enseñar, pero al que no tienen interés en aproximarse.

Pasamos, luego, a considerar su obra más significativa, en lo que concierne al género documental. Con Jogo de cena, Coutinho provocó una reflexión sobre el género, que lo consagró como artista y profesional de la comunicación audiovisual. Con tal propósito, desmitificaba su propio producto, su propio arte, afirmando que cualquier cosa era documental y cualquier cosa era ficción; es decir, podemos construir nuestras verdades y ellas constituyen la base de la construcción de una buena historia.

Al final, llegamos a la conclusión de que Eduardo Coutinho fue más que un documentalista. En realidad, podemos considerarlo un teórico/técnico/esteta, pues, a partir de sus técnicas y su estética, muchas teorías han podido llegar a edificarse, especialmente por parte de aquellos que han intentado reproducir sus técnicas y estética, defendiéndolas con base en los resultados obtenidos. Se trata de una necesidad de desarrollo académico aplicado, en que el experimento viene antes de las conclusiones, que no son otra cosa que la interpretación de los resultados empíricos. 
El mundo se quedó sin Eduardo Coutinho, pero su legado perdura, enseñándonos a entender qué temas pueden incluirse en el género documental (es decir, todos los temas), las maneras posibles para elaborar las obras (es decir, cualquiera manera), la frontera entre ficción y realidad (es decir, ninguna frontera, aparte de nuestros ojos) y, finalmente, el valor de la memoria y la emoción, presentes en todos los documentales en que se aplica el rescate de la memoria de la imagen. Efectivamente, Eduardo Coutinho es un ejemplo para el documental.

\section{Investigación financiada}

Financiadora: Pró-reitoria de Pesquisa (PROPe), edital "PrimeirosProjetos", proceso $\underline{0242 / 001 / 14-\mathrm{PROPe} / \mathrm{CDC}}$

\section{Referencias bibliográficas}

R Bedoya; I L Frías (2003): Ojos bien abiertos - el lenguaje de las imágenes en movimiento. Lima: Fondo de desarrollo editorial.

J C Bernardet (2003): Cineastas e imagens do povo. São Paulo:Companhia das Letras.

M Galán Zarzuelo (2012): "Cine militante y videoactivismo: los discursos audiovisuales de losmovimientossociales”. Em Revista Comunicación, v.1, nº 10, pp. 1091-1102.

H Gervaiseau (2012): O abrigo do tempo - abordagens cinematográficas da passagem do tempo. São Paulo: Alameda.

L Manovich (2005): El lenguaje de los nuevos medios de comunicación - la imagen en la era digital. Barcelona: Paidós.

C Mateos; M Rajas (2014): "Videoactivismo: concepto y rasgos". InG Bustos et al (Eds.) (2014): Videoactivismo - acción política, cámara en mano. Cuadernos Artesanos de Comunicación. La Laguna: Latina.

B Nichols (1997): La representación de la realidad. Barcelona: Paidós.

R Odin (1984). Film documentaire, lectura documentarisante: cinemas et réalités. Paris: CIEREC Université de Saint-Étienne.

F P Ramos (2008): Mas afinal... o que é mesmo documentário? São Paulo: SENAC.

V Reia-Baptista, A Burn, M Reid, M Cannon (2014): "Literacía Cinematográfica: Reflexión sobre los modelos de educación cinematográfica en Europa". En: Revista Latina de Comunicación Social, n 69 , pp. 354 - 367. http://www.revistalatinacs.org/069/paper/1015_UK/18ves.html

D Renó; E Gonçalves (2014): "Diversidadenal inguagem: a intertextualidade cinematográfica em A Antena". In: E Gonçalves (Ed.) (2014): El pensamiento comunicacional a través del cine. Quito: CIESPAL.

D Renó (2013): "Diversidade de modelos narrativos para documentários transmídia". En: Revista DOC Online, nº 14 - agosto, 2013. www.doc.ubi.pt - pp 93-112. 
D Renó (2012): Cinema documental interativo e linguagens audiovisuais participativas: como produzir. Tenerife: Universidad La Laguna.

D Renó (2008): "El montaje audiovisual como base narrativa para el cine documental interactivo: nuevos estudios". En: Revista Latina de Comunicación Social, nº 63, pp. 83 -90. La Laguna (Tenerife): Universidad de La Laguna. Recuperado el 10 de agosto de 2014 de: http://www.ull.es/publicaciones/latina/_2008/08_Brasil/2008_Denis_Porto.html.

D Renó (2007): "Youtube, el mediador de la cultura popular en el ciberespacio". En: Revista Latina de Comunicación Social, $\mathrm{n}^{\circ}$ 62. La Laguna (Tenerife): Universidad de La Laguna. Recuperado el 21 de diciembre de 2014 de: http://www.ull.es/publicaciones/latina/200717Denis_Reno.htm

F Vanoye.; A Goliot-Iété (2008): Ensaio sobre a análise fílmica. Campinas: Papirus.

I Xavier (1983). A experiência do cinema: antologia. Rio de Janeiro: Graal

\section{Filmografía}

“Cabra marcado para morrer" (1985), de Eduardo Coutinho.

“Santa Marta-duas semanas no morro" (1987), de Eduardo Coutinho.

“Babilônia 2000” (2000), de Eduardo Coutinho.

“Edificio Master" (2002), de Eduardo Coutinho.

“Jogo de cena" (2007), de Eduardo Coutinho.

\section{Cómo citar este artículo / Referencia normalizada}

D Renó, C Campalans Moncada, L Renó (2015): “Técnicas y lenguajes documentales por el brasileño Eduardo Coutinho". Revista Latina de Comunicación Social, 70, pp. 174 a 186. http://www.revistalatinacs.org/070/paper/1041br/11es.html DOI: $10.4185 / R L C S-2015-1041$

Artículo recibido el 14 de diciembre de 2014. Aceptado el 22 de febrero. Publicado el 28 de febrero de 2015. 